\title{
ESTUDIOS GENERALES Y LAS MATEMÁTICAS
}

Mario Efraín Góngora Santa Cruz

$\mathrm{U}$

no de los aspectos más importantes de la nueva

Universitaria $\mathrm{N}^{\circ} 30220$ promulgada el 09-07-2014

es, "formar profesionales de alta calidad, de manera integral y con pleno sentido de responsabilidad social, de acuerd a las necesidades del país". El futuro profesional deberá estar preparado para actuar con eficacia, sentido crítico y filosofía de vida en todos los aspectos: personal, social y laboral.

Para lograr la calidad en la formación profesional, mencionada Ley, dispone la implementación de los Estudio Generales Obligatorios, en la primera etapa de formació profesional del sistema universitario. Resalta la investigació científica, promueve la capacitación continua de la docencia impulsa la responsabilidad social y restaura el servicio soci

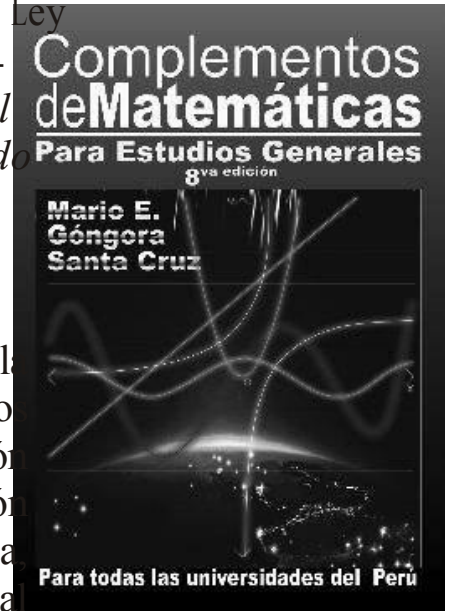
universitario.

Los Estudios Generales constituyen un periodo inicial de la formación profesional, tiene como finalidad formar en los estudiantes hábitos de análisis, reflexión y criticidad; además proporciona instrumentos intelectuales indispensables para alcanzar una educación básica universitaria, la misma que permitirá que se consoliden en la carrera que elijan de acuerdo a sus intereses, aptitudes y vocación.

Los Estudios Generales tienen como objetivo que los estudiantes adquieran Competencias Genéricas, entendidas éstas, como el conjunto de conocimientos, habilidades, destrezas comunes a todas las profesiones. El propósito es lograr la formación integral de la persona, para desempeñarse con éxito en todos los ámbitos. La Matemática es una asignatura ineludible en esta Etapa de Formación.

La matemática es una ciencia rigurosa transversal, con esquema coherente y secuencia lógica. Desarrolla el pensamiento lógico, riguroso y creativo; así como las habilidades cognitivas de análisis, síntesis, abstracción, generalización y evaluación. Es el más importante instrumento de formación, orden, disciplina y resolución de problemas, especialmente en la etapa inicial de todas y cada una de las carreras profesionales.

La matemática es la asignatura básica indispensable, el cimiento sólido, para el estudio de todas las asignaturas de las diferentes escuelas profesionales. La enseñanza se debe impartir de manera reflexiva y con conocimiento de su estructura; requiere de una buena planificación y un buen libro que contenga los temas y sus proyecciones, para lograr la fidelización del aprendizaje.

El libro de "Complementos de Matemáticas para Estudios Generales" octava edición, es producto de la experiencia en la enseñanza en diferentes niveles de la educación (educación básica regular, educación técnica y educación superior universitaria), desarrolla los conceptos básicos de la matemática, indispensables para lograr los objetivos de los Estudios Generales y alcanzar la calidad del futuro profesional.

Los 19 capítulos del libro contienen los requerimientos básicos de la matemática en estudios generales. Las definiciones, axiomas, teoremas, ejercicios y problemas, son expuestos, demostrados y resueltos con secuencia lógica y metodología apropiada, que facilita el uso y preferencia del lector. Así mismo, el libro contiene capítulos necesarios para seguir los cursos de la matemática avanzada en todas las carreras profesionales. 